\title{
Older fusion-surgery age in congenital scoliosis patients is a risk factor for extended length of stay, more estimated blood loss, longer fused segments and higher medical costs: a retrospective study
}

Xiran Chai, Guanfeng Lin, Shengru Wang, Yang Yang, Zhe Su, You Du, Xiaolin Xu, Xiaohan Ye, Jianxiong Shen and Jianguo Zhang ${ }^{*}$

\begin{abstract}
Background: Contradictory opinions about whether early correction and fusion surgeries should be performed for congenital scoliosis (CS) patients at a young age exist. The objectives of this study were to analyze the association between patient characteristics and fusion-surgery outcomes in CS patients treated with spinal correction and fusion surgeries and to report risk factors for extended length of stay (LOS), more estimated blood loss (EBL), longer fused segments and higher medical costs.

Methods: We analyzed data of 1,207 CS inpatients treated with fusion surgeries in our institute from January 2010 December 2019. All patients underwent spinal X-ray, CT, MRI, echocardiogram and urogenital ultrasound. We analyzed demographic and clinical information and outcome measures, including LOS, EBL, fused segments and medical costs.

Results: Age at fusion ( $O R=1.053 ; p<0.001)$, musculoskeletal defects $(\mathrm{OR}=1.670 ; p=0.004)$ and thoracic deformity $(\mathrm{OR}=1.519 ; p=0.03)$ were risk factors for extended LOS. Age at fusion $(\mathrm{OR}=1.117 ; p<0.001)$, male sex $(\mathrm{OR}=1.813$; $p<0.001)$, mixed defects $(\mathrm{OR}=1.662 ; p=0.027)$ and failure of formation $(\mathrm{OR}=1.718 ; p=0.021)$ were risk factors for more EBL. Age at fusion $(\mathrm{OR}=1.213 ; p<0.001)$ was a risk factor for longer fused segments. Age at fusion $(\mathrm{OR}=$ $1.091 ; p<0.001)$ and thoracic deformity $(\mathrm{OR}=1.853 ; p=0.004)$ were risk factors for higher medical costs.
\end{abstract}

Conclusions: We found that older age at fusion in CS patients is a risk factor for extended LOS, more EBL, longer fused segments and higher medical costs with the risk increasing by 5-21\% for each year of age. Other identified risk factors include thoracic deformity for extended LOS; longer fused segments, higher medical costs, and musculoskeletal defects for extended LOS; and CS type (FF and MD) and sex (male) for more EBL.

Keywords: Congenital scoliosis, Risk factor for fusion surgery, Length of stay, Estimated blood loss, Medical costs

\footnotetext{
*Correspondence: jgzhang_pumch@yahoo.com

Departments of Orthopaedic Surgery, Peking Union Medical College Hospital (PUMCH), 1st Shuai Fu Yuan Hutong, Dongcheng District, 100730 Beijing,

People's Republic of China
}

C The Author(s). 2021 Open Access This article is licensed under a Creative Commons Attribution 4.0 International License, which permits use, sharing, adaptation, distribution and reproduction in any medium or format, as long as you give appropriate credit to the original author(s) and the source, provide a link to the Creative Commons licence, and indicate if changes were made. The images or other third party material in this article are included in the article's Creative Commons licence, unless indicated otherwise in a credit line to the material. If material is not included in the article's Creative Commons licence and your intended use is not permitted by statutory regulation or exceeds the permitted use, you will need to obtain permission directly from the copyright holder. To view a copy of this licence, visit http://creativecommons.org/licenses/by/4.0/. The Creative Commons Public Domain Dedication waiver (http://creativecommons.org/publicdomain/zero/1.0/) applies to the data made available in this article, unless otherwise stated in a credit line to the data. 


\section{Background}

Congenital scoliosis (CS) is the lateral curvature of the spine resulting from vertebral deformities that develop during the 4th to 6th weeks of gestation and are present at birth. CS was reported to have an incidence of approximately 1 in every 1,000 live births [1]. Surgery for CS is indicated for cases of documented/potential progressive curvature and/or neurological deficits and remains one of the most challenging surgeries in orthopedics.

Unlike the etiologies of other types of scoliosis, such as idiopathic, neuromuscular and syndromic, the deformitycausing forces of CS are due to only congenital vertebral malformation. Once the congenital vertebral malformation is corrected, most scoliosis will no longer progress. However, if the congenital vertebral malformation is left intact, $50 \%$ of CS displays very rapid progression [2]. The progression of CS depends on the imbalance of growth potential and the growth rate of the spine. The growth rate of the spine is not uniform, and there are periods of accelerated growth, before age 5 and during the adolescence growth spurt [3]. Thus, early congenital deformity correction and spine fusion might be beneficial for patients to prevent scoliosis from progressing. However, there are still contradictory opinions about whether early correction and fusion surgeries should be performed for patients at a younger age. Extended length of stay (LOS), more estimated blood loss (EBL), and long fusion segments are important concerns against early surgeries. However, the association between patient characteristics, including age at surgeries, and LOS, EBL and fusion segments has scarcely been reported.

The objectives of this study were to systematically analyze the association between patient characteristics and surgery outcomes and to report risk factors for extended LOS, more EBL, longer fused segments and higher medical costs.

\section{Methods \\ Patients}

We retrospectively searched the inpatient database for cases in which patients were admitted for CS and underwent spine fusion surgeries from January 2010 to December 2019 in our institute using ICD-10 codes (Q67.501, Q67.502). The inclusion criteria were (1) patients diagnosed with CS and (2) patients who underwent primary posterior spine fusion surgery with or without osteotomies. In total, 1,207 inpatients were included in our study. The exclusion criteria were as follows: (1) patients with scoliosis caused by non-congenital factors, such as idiopathic and neuromuscular factors, and (2) patients who underwent non-fusion surgeries or in whom an anterior/anteriorposterior approach was employed.

Demographic information, including sex and age at the initial operation, was directly extracted from the inpatient database. The CS types, namely failure of formation (FF), failure of segmentation (FS) and mixed defects (MD), were diagnosed from the patients' $\mathrm{X}$-ray and spine CT [20,21]. Echocardiogram; urogenital ultrasound; spine imaging; including MRI, X-ray and CT; and systemic physical examination were undertaken in all patients to screen and diagnose associated anomalies. Primary outcomes, including the length of stay, estimated blood loss, fusion segments (two vertebral bodies and an intervertebral disc were defined as two levels or one segment), medical costs and complications, were extracted from medical records and analyzed.

\section{Statistical analysis}

All statistical analyses were performed using SPSS Statistics Version 23 (IBM, Armonk, New York). An independent Student's t test was used to analyze continuous data with a normal distribution. A nonparametric test was used to analyze continuous data with a non-normal distribution. The chi-square test was used to analyze enumerated data. In the univariate analysis, factors with a $P$-value $<0.1$ were included as potential risk factors in multiple logistic regression analysis to determine significant independent risk factors. A $P$-value $<0.05$ was considered statistically significant in multivariate analysis. All graphs were plotted by GraphPad Prism 8 (Version 8.4.0, GraphPad Software, LLC.).

\section{Results}

From January 2010 to December 2019, a total of 1,207 inpatients who underwent instrumented fusion surgery were included in this study. The average age at the time of fusion surgery was $12.7 \pm 8.2$ years old and is significantly lower in male than in female (11.51 vs. $13.72, p<$ $0.001) .564$ patients $(46.7 \%)$ were male, while 643 patients $(53.3 \%)$ were female. $50 \%$ of patients $(n=604)$ had failure of formation, $18.5 \%$ of patients $(n=223)$ had failure of segmentation and the remaining $31.5 \%$ of patients $(n=380)$ had mixed defects. Regarding vertebral anomaly location, cervical, thoracic and lumbar vertebral anomalies were found in 67 patients (5.6\%), 930 patients (77.1\%) and 423 patients (35.1\%), respectively (Table 1 ).

With regard to comorbidity information, the incidences of intraspinal, musculoskeletal, cardiac, gastrointestinal and urogenital defects were $28.6 \%(n=345)$, $15.5 \%(n=187), 13.7 \%(n=165), 3.6 \%(n=44)$ and $5.8 \%(n=70)$, respectively. Twenty-three point nine percent $(n=288)$ of patients had an extended length of stay (defined as LOS $>14$ days), $20.2 \%(n=244)$ of patients had more estimated blood loss (defined as EBL $>800$ $\mathrm{ml}), 48.6 \%(n=587)$ of patients had more than 8 levels fused and $22.0 \%(n=266)$ of patients had medical costs greater than 20,000 USD (Table 1). 
Table 1 Basic information

\begin{tabular}{ll}
\hline Demographic information & \\
Sample size & 1,207 \\
Sex (male/female) & $564 / 643$ \\
Age at fusion (year) & $12.69 \pm 8.19$ \\
Age at fusion (male) & $11.51 \pm 7.82$ \\
Age at fusion (female) & $13.72 \pm 8.38(p<0.001)$ \\
Deformity information & \\
CS type (FF/FS/MD) & $604 / 223 / 380(50.04 \% / 18.48 \% / 31.48 \%)$ \\
Cervical involved & $5.55 \%(n=67)$ \\
Thoracic involved & $77.05 \%(n=930)$ \\
Lumbar involved & $35.05 \%(n=423)$ \\
Comorbidity information & \\
Intraspinal & $28.58 \%(n=345)$ \\
Musculoskeletal & $15.49 \%(n=187)$ \\
Cardiac & $13.67 \%(n=165)$ \\
Gastrointestinal & $3.65 \%(n=44)$ \\
Urogenital & $5.80 \%(n=70)$ \\
Outcome information & \\
Length of stay $>14$ days & $23.86 \%(n=288)$ \\
Estimated blood loss $>800 \mathrm{ml}$ & $20.21 \%(n=244)$ \\
Fusion segments $>8$ levels & $48.63 \%(n=587)$ \\
Medical costs $>20,000$ USD & $22.04 \%(n=266)$ \\
\hline
\end{tabular}

To avoid missing potential risk factors, $P$-values $<0.1$ were considered statistically significant in the univariate analysis. After the univariate analysis, significant risk factors for extended LOS included sex, age at operation, CS type, thoracic deformity, intraspinal defects and musculoskeletal defects (Table 2). Among risk factors with $P$ value $<0.1$ in the univariate analyses, age at operation $(\mathrm{OR}=1.053$ [1.036-1.071]; $p<0.001)$, musculoskeletal defects $(\mathrm{OR}=1.670[1.173-2.376] ; p=0.004)$ and thoracic deformity $(\mathrm{OR}=1.519[1.042-2.215] ; p=0.03)$ were found to be independent risk factors for extended LOS in multivariate analyses (Fig. 1).

In the analysis of EBL risk factors, sex, age at operation, CS type, thoracic deformity and intraspinal defects were recognized as potential risk factors after univariate analysis. After multivariate analysis, age at operation $(\mathrm{OR}=1.117$ [1.094-1.141]; $p<0.001)$, male $(\mathrm{OR}=1.813$ [1.319-2.494]; $p<0.001)$, CS types of mixed defects $(\mathrm{OR}=1.662[1.061-2.604] ; p=0.027)$ and failure of formation $(\mathrm{OR}=1.718$ [1.087-2.717]; $p=0.021)$ were found to be independent risk factors for estimated blood loss greater than $800 \mathrm{ml}$ (Fig. 2) (Table 3).

Regarding the analysis of long-segment fusion, age at operation $(\mathrm{OR}=1.213[1.176-1.251] ; p<0.001)$, thoracic deformity $\quad(\mathrm{OR}=11.297 \quad[6.846-18.644] ; \quad p<0.001)$, intraspinal defects $(\mathrm{OR}=3.416$ [2.383-4.897]; $p<0.001)$, CS types of failure of segmentation $(\mathrm{OR}=3.638$ [2.3315.667]; $p<0.001)$, mixed defects $(\mathrm{OR}=1.873[1.315-$

Table 2 Univariate analysis and multivariate analysis of LOS risk factors

\begin{tabular}{llll}
\hline Parameters & LOS $>16$ days & LOS $\leq 16$ days & $p$ \\
Univariate analysis & & & 0.089 \\
Sex (male/female) & $122 / 166$ & $442 / 477$ & $<0.001$ \\
Age at fusion & $15.70 \pm 10.15$ & $11.75 \pm 7.23$ & 0.001 \\
CS type (FF/FS/MD) & $41.3 \% / 19.1 \% / 39.6 \%$ & $52.8 \% / 18.3 \% / 28.9 \%$ & 0.139 \\
Cervical deformity & $7.3 \%$ & $5.0 \%$ & 0.001 \\
Thoracic deformity & $84.4 \%$ & $74.8 \%$ & 0.122 \\
Lumbar deformity & $31.3 \%$ & $36.2 \%$ & 0.002 \\
Intraspinal defects & $35.8 \%$ & $26.3 \%$ & $<0.001$ \\
Musculoskeletal defects & $22.2 \%$ & $13.4 \%$ & 0.363 \\
Cardiac defects & $15.3 \%$ & $13.2 \%$ & 0.368 \\
Gastrointestinal defects & $2.8 \%$ & $3.8 \%$ & 0.214 \\
Urogenital defects & $7.3 \%$ & $5.3 \%$ & $95 \% \mathrm{Cl}$ \\
Parameters & $p$ & 0 Odds ratio & $1.036-1.071$ \\
Multivariate analysis & $<0.001$ & 1.053 & $1.173-2.376$ \\
Age at fusion & 0.004 & 1.670 & $1.042-2.215$ \\
Musculoskeletal defects & 0.030 & 1.519 & $0.876-1.620$ \\
Thoracic deformity & 0.264 & 1.191 & $0.813-1.433$ \\
Intraspinal defects & 0.595 & 1.080 & \\
Sex & & & \\
\hline
\end{tabular}




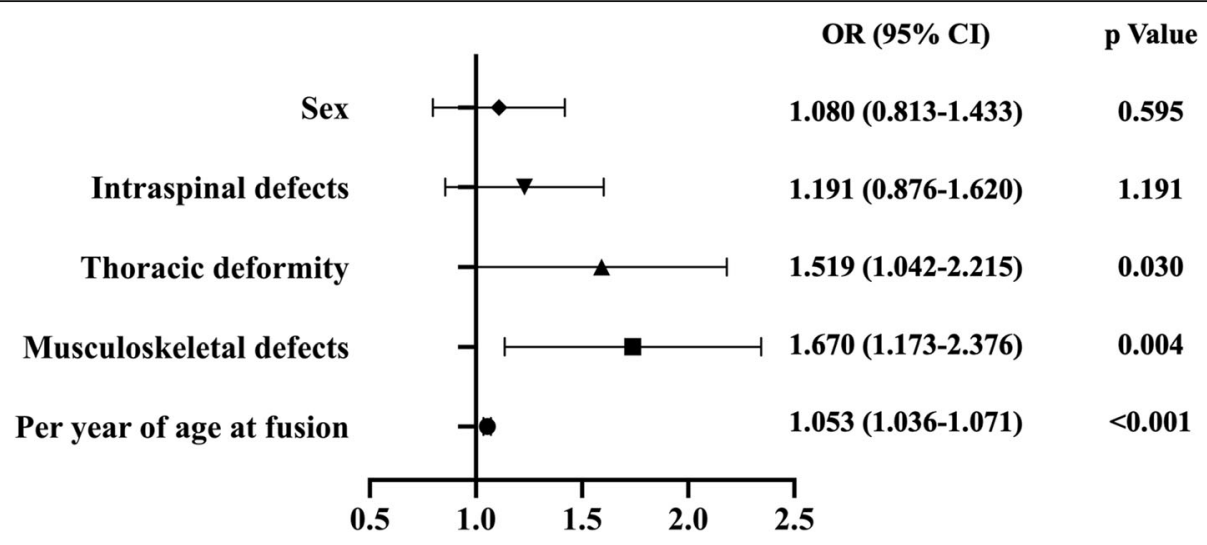

Fig. 1 Odds ratio and $p$ value of multivariate analysis of extended length of stay (length of stay > 16 days)

2.669]; $p=0.001)$ and cervical deformity $(\mathrm{OR}=2.071$ [1.093-3.925]; $p=0.026)$ were identified as independent risk factors for more than 8 levels fused (Fig. 3) (Table 4).

When analyzing risk factors for medical costs, we found that patients with medical costs greater than 20,000 USD had older age at operation $(p<0.001)$, different CS type distribution $(p<0.001)$, more patients with thoracic deformity $(p<0.001)$ and more patients with intraspinal $(p=0.009)$ and urogenital defects $(p=$ $0.024)$ in univariate analysis. Although lumbar deformity had a $P$-value $<0.1$ in univariate analysis, we excluded it from multivariate analysis, as it appeared to be a protective factor for higher medical costs. After multivariate analysis, age at operation $(\mathrm{OR}=1.091[1.071-1.112] ; p<$ $0.001)$ and thoracic deformity $(\mathrm{OR}=1.853$ [1.222-2.810]; $p=0.004$ ) were identified as independent risk factors for medical costs greater than 20,000 USD (Fig. 4) (Table 5).

The total osteotomy rate in our CS cohort is $56.7 \%$ $(n=684)$ (Table 6). After analyzing the correlation between osteotomy rate and LOS, EBL and medical costs, we found that patients who underwent osteotomy had lower incidences of LOS > 14 days $(37.6 \%$ vs. $42.6 \%, p=$
$0.075)$ and medical costs $>20,000$ USD (20.0 \% vs. $24.7 \%$, $p=0.059)$ and higher incidences of EBL $>800 \mathrm{ml}(22.4 \%$ vs. $17.4 \%, p=0.036$ ).

As for the analysis of complication information (Table 7), we found that the total complication rate in our study is $13.2 \%(n=159)$ and complication rate in patients of $0-3$ years old and in patients of more than 3 years old showed no statistically significance $(8.7 \%$ vs. $13.8 \%, p=0.109$ ). Rates for specific complications were $2.0 \%$ for implantation-related complications, $2.0 \%$ for adding-on and decompensation, $1.3 \%$ for incisionrelated complications, $1.1 \%$ for infections, $3.3 \%$ for pleural effusion and hemothorax, $2.0 \%$ for neurologic complications and $0.4 \%$ for CSF leakage.

\section{Discussion}

The spine undergoes a bimodal growth spurt: once during the first 3 to 5 years of life and again during puberty [3-5]. Thus, congenital vertebral malformations (CVMs) in patients at early ages would result in rapid progression of scoliosis during these two growth spurts and lead to severe prognosis until the skeleton fully matures. As a

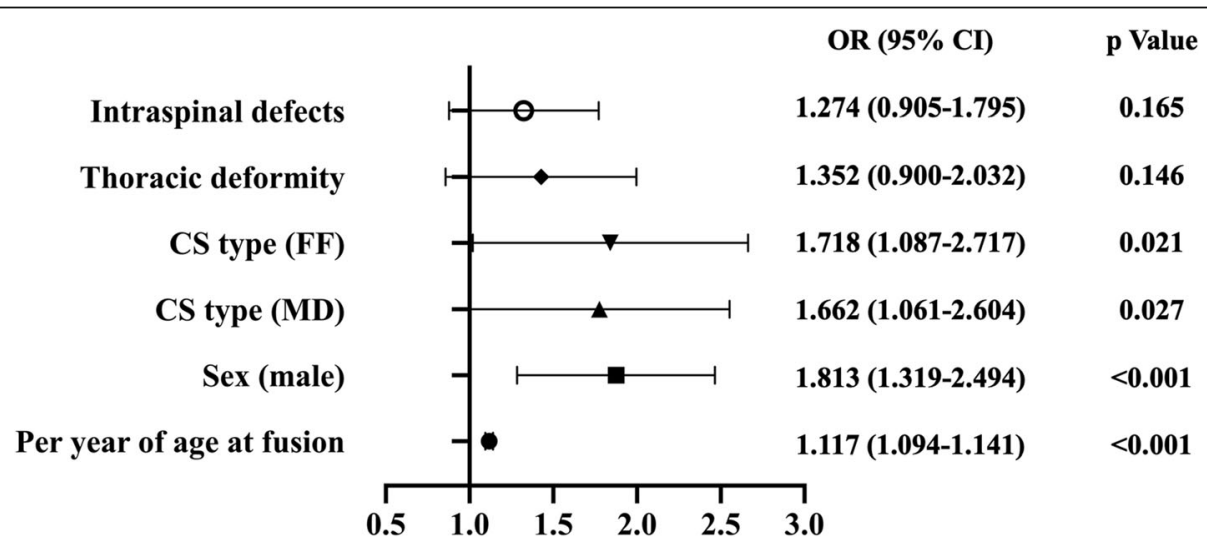

Fig. 2 Odds ratio and $p$ value of multivariate analysis of estimated blood loss during fusion surgery (estimated blood loss $>800 \mathrm{ml}$ ) 
Table 3 Univariate analysis and multivariate analysis of EBL risk factors

\begin{tabular}{|c|c|c|c|}
\hline Parameters & $\mathrm{EBL}>800 \mathrm{ml}$ & $\mathrm{EBL} \leq 800 \mathrm{ml}$ & $p$ \\
\hline \multicolumn{4}{|l|}{ Univariate analysis } \\
\hline Sex (male/female) & $128 / 116$ & $436 / 527$ & 0.045 \\
\hline Age at fusion & $18.44 \pm 8.56$ & $11.23 \pm 7.42$ & $<0.001$ \\
\hline CS type (FF/FS/MD) & $45.9 \% / 16.8 \% / 37.3 \%$ & $51.1 \% / 18.9 \% / 30.0 \%$ & 0.091 \\
\hline Cervical deformity & $7.0 \%$ & $5.2 \%$ & 0.279 \\
\hline Thoracic deformity & $82.0 \%$ & $75.8 \%$ & 0.041 \\
\hline Lumbar deformity & $36.5 \%$ & $34.7 \%$ & 0.600 \\
\hline Intraspinal defects & $34.8 \%$ & $27.0 \%$ & 0.016 \\
\hline Musculoskeletal defects & $17.6 \%$ & $15.0 \%$ & 0.303 \\
\hline Cardiac defects & $12.7 \%$ & $13.9 \%$ & 0.623 \\
\hline Gastrointestinal defects & $3.7 \%$ & $3.6 \%$ & 0.968 \\
\hline Urogenital defects & $6.6 \%$ & $5.6 \%$ & 0.571 \\
\hline Parameters & $p$ & Odds ratio & $95 \%$ Cl \\
\hline \multicolumn{4}{|l|}{ Multivariate analysis } \\
\hline Age at fusion & $<0.001$ & 1.117 & $1.094-1.141$ \\
\hline Sex (male) & $<0.001$ & 1.813 & $1.319-2.494$ \\
\hline CS type & 0.047 & - & - \\
\hline FS & - & 1 (Reference) & \\
\hline MD & 0.027 & 1.662 & $1.061-2.604$ \\
\hline FF & 0.021 & 1.718 & $1.087-2.717$ \\
\hline Thoracic deformity & 0.146 & 1.352 & $0.900-2.032$ \\
\hline Intraspinal defects & 0.165 & 1.274 & $0.905-1.795$ \\
\hline
\end{tabular}

result, some surgeons recommended that early surgery and CVM correction should be performed to prevent scoliosis from progressing. However, early surgery, especially long-segment fusion, might increase the risk of damaged development of the lung, thoracic cage and vertebrae. These controversies have lasted for decades. There is still a lack of studies in large-scale samples reporting effect of fusion age on surgical safety and outcomes.
The most prevalent concern about early fusion is damaged pulmonary function. CS patients treated with early spinal fusion have lower forced vital capacity, forced expiratory volume, vital capacity and total lung capacity than healthy children, and the impairment of pulmonary function is more severe in patients with thoracic fusions [6]. Early spinal fusion and longer fused segments are also associated with more severe damage to vital capacity $[7,8]$. However, these studies all compared patients

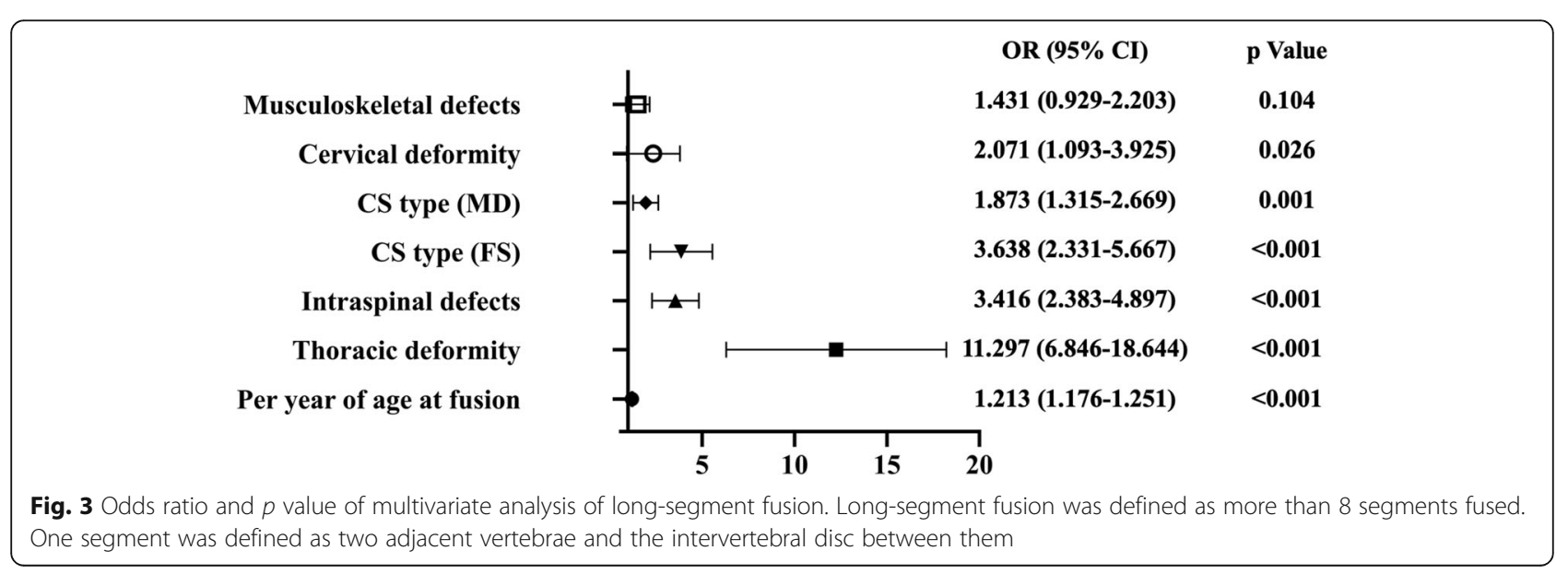


Table 4 Univariate analysis and multivariate analysis of long-segment fusion risk factors

\begin{tabular}{|c|c|c|c|}
\hline Parameters & Fused segments $>8$ & Fused segments $\leq 8$ & $p$ \\
\hline \multicolumn{4}{|l|}{ Univariate analysis } \\
\hline Sex (male/female) & $225 / 362$ & $339 / 281$ & $<0.001$ \\
\hline Age at fusion & $16.61 \pm 7.80$ & $8.98 \pm 6.69$ & $<0.001$ \\
\hline CS type (FF/FS/MD) & $29.1 \% / 30.0 \% / 40.9 \%$ & $69.8 \% / 7.6 \% / 22.6 \%$ & $<0.001$ \\
\hline Cervical deformity & $7.3 \%$ & $3.9 \%$ & 0.009 \\
\hline Thoracic deformity & $93.4 \%$ & $61.6 \%$ & $<0.001$ \\
\hline Lumbar deformity & $20.3 \%$ & $49.0 \%$ & $<0.001$ \\
\hline Intraspinal defects & $45.3 \%$ & $12.7 \%$ & $<0.001$ \\
\hline Musculoskeletal defects & $20.8 \%$ & $10.5 \%$ & $<0.001$ \\
\hline Cardiac defects & $15.0 \%$ & $12.0 \%$ & 0.194 \\
\hline Gastrointestinal defects & $2.4 \%$ & $4.8 \%$ & 0.023 \\
\hline Urogenital defects & $5.8 \%$ & $5.8 \%$ & 0.992 \\
\hline Parameters & $p$ & Odds ratio & $95 \% \mathrm{Cl}$ \\
\hline \multicolumn{4}{|l|}{ Multivariate analysis } \\
\hline Age at fusion & $<0.001$ & 1.213 & $1.176-1.251$ \\
\hline Thoracic deformity & $<0.001$ & 11.297 & $6.846-18.644$ \\
\hline Intraspinal defects & $<0.001$ & 3.416 & $2.383-4.897$ \\
\hline CS type & $<0.001$ & - & - \\
\hline $\mathrm{FF}$ & - & 1 (Reference) & \\
\hline FS & $<0.001$ & 3.638 & $2.331-5.667$ \\
\hline MD & 0.001 & 1.873 & $1.315-2.669$ \\
\hline Cervical deformity & 0.026 & 2.071 & $1.093-3.925$ \\
\hline Musculoskeletal defects & 0.104 & 1.431 & $0.929-2.203$ \\
\hline
\end{tabular}

with severe congenital deformities that require early surgical correction to healthy people or those with mild congenital deformities that can be treated with conservative treatment. Patients with severe congenital deformities would have lower pulmonary function by nature; thus, we could not conclude that their more severe lung function damage is due to early spinal fusion or compression caused by severe deformities from these studies.
Complications, such as the crankshaft phenomenon, are another problem. The crankshaft phenomenon was reported to be positively associated with earlier spinal fusions [9]. In short, there are still concerns, such as pulmonary function damage and other complications, such as the crankshaft phenomenon, about the effects of fusion surgeries on immature spines among spinal surgeons.

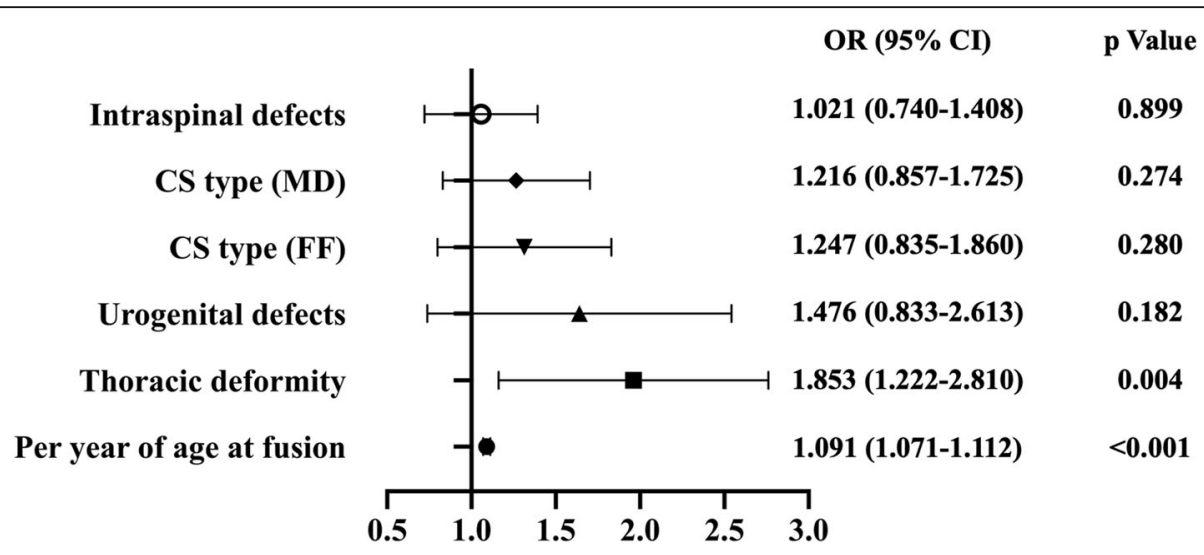

Fig. 4 Odds ratio and $p$ value of multivariate analysis of higher medical costs (medical costs > 20,000 USD) 
Table 5 Univariate analysis and multivariate analysis of medical costs risk factors

\begin{tabular}{|c|c|c|c|}
\hline Parameters & Medical costs $>20 \mathrm{k}$ USD & Medical costs $\leq 20 \mathrm{k}$ USD & $p$ \\
\hline \multicolumn{4}{|l|}{ Univariate analysis } \\
\hline Sex (male/female) & $126 / 140$ & $438 / 503$ & 0.812 \\
\hline Age at fusion & $17.67 \pm 9.10$ & $11.28 \pm 7.33$ & $<0.001$ \\
\hline CS type (FF/FS/MD) & $38.0 \% / 24.4 \% / 37.6 \%$ & $53.5 \% / 16.8 \% / 29.8 \%$ & $<0.001$ \\
\hline Cervical deformity & $5.6 \%$ & $5.5 \%$ & 0.943 \\
\hline Thoracic deformity & $86.1 \%$ & $74.5 \%$ & $<0.001$ \\
\hline Lumbar deformity & $28.9 \%$ & $36.8 \%$ & 0.018 \\
\hline Intraspinal defects & $35.0 \%$ & $26.8 \%$ & 0.009 \\
\hline Musculoskeletal defects & $16.2 \%$ & $15.3 \%$ & 0.731 \\
\hline Cardiac defects & $15.0 \%$ & $13.3 \%$ & 0.462 \\
\hline Gastrointestinal defects & $2.3 \%$ & $4.0 \%$ & 0.171 \\
\hline Urogenital defects & $8.6 \%$ & $5.0 \%$ & 0.024 \\
\hline Parameters & $p$ & Odds ratio & $95 \%$ Cl \\
\hline \multicolumn{4}{|l|}{ Multivariate analysis } \\
\hline Age at fusion & $<0.001$ & 1.091 & $1.071-1.112$ \\
\hline Thoracic deformity & 0.004 & 1.853 & $1.222-2.810$ \\
\hline Urogenital defects & 0.182 & 1.476 & $0.833-2.613$ \\
\hline CS type & 0.448 & - & - \\
\hline FF & - & 1 (Reference) & \\
\hline FS & 0.280 & 1.247 & $0.835-1.860$ \\
\hline MD & 0.274 & 1.216 & $0.857-1.725$ \\
\hline Intraspinal defects & 0.899 & 1.021 & $0.740-1.408$ \\
\hline
\end{tabular}

Another concern is that pedicle screws have to pass through the neurocentral cartilage (NCC), which is responsible for the growth of the pedicles and the posterior vertebral body, and the NCC begins to fuse at 3 to 5 years of age [10]. Thus, there is concern that pedicle screw instrumentation in patients younger than 5 years of age may affect the development of the vertebral body and spinal canal. Until now, there has been no evidence

Table 6 Osteotomy information

\begin{tabular}{lll}
\hline Osteotomy information & & \\
\hline Total osteotomy rate & $56.7 \%(n=684)$ & \\
Correlation between osteotomy and LOS & & \\
LOS $>14$ days in osteotomy group & $37.6 \%(257 / 684)$ & $p=0.075$ \\
LOS $>14$ days in non-osteotomy group & $42.6 \%(223 / 523)$ & \\
Correlation between osteotomy and EBL & & \\
EBL $>800 \mathrm{ml}$ in osteotomy group & $22.4 \%(153 / 684) \quad p=0.036^{*}$ \\
EBL $>800 \mathrm{ml}$ in non-osteotomy group & $17.4 \%(91 / 523)$ & \\
Correlation between osteotomy and & & \\
medical cost & & \\
Cost $>20,000$ USD in osteotomy group & $20.0 \%(137 / 684)$ & $p=0.059$ \\
Cost $>20,000 U S D$ in non-osteotomy & $24.7 \%(129 / 523)$ & \\
group & &
\end{tabular}

of iatrogenic vertebral dysplasia or spinal stenosis due to pedicle screws. Michael et al. [11] studied the use of pedicle screws in pediatric patients younger than 2 years old and concluded that pedicle screw fixation can be safely performed without more complications related to pedicle screw insertion or negative effects on vertebral growth. Several later studies corroborated that the growth rates of the vertebral body and spinal canal were not affected by pedicle screw instrumentation at a young age [12-14]. In terms of the effect on the growing spine,

Table 7 Complication information

\begin{tabular}{ll}
\hline Complication information & \\
\hline Total complications & $13.2 \%(n=159)$ \\
$\quad$ Complications in 0-3 year-old patients & $8.7 \%(12 / 138) \quad p=0.109$ \\
$\quad$ Complications in > 3 year-old patients & $13.8 \%(147 / 1069)$ \\
Implantation-related complications & $2.0 \%(n=23)$ \\
Adding-on and decompensation & $2.0 \%(n=23)$ \\
Incision-related complications & $1.3 \%(n=16)$ \\
Infections & $1.1 \%(n=13)$ \\
Pleural effusion, hemothorax & $3.3 \%(n=40)$ \\
Neurologic complications & $2.0 \%(n=24)$ \\
CSF leakage & $0.4 \%(n=5)$ \\
\hline
\end{tabular}


pedicle screw instrumentation is widely accepted to be safe in infants.

By directly analyzing the interrelationship between age at fusion and patient outcomes, Wu et al. [15] found that older age was an independent risk factor for the development of pulmonary complications after posterior spinal instrumentation and fusion in CS patients. According to our data in this study, we also found that older age at surgery is a risk factor for extended LOS, more EBL, longer fused segments and higher medical costs with the risk increasing by $5-21 \%$ for each year increase in patient age at the time of fusion surgery (Figs. 1, 2, 3 and 4). This result demonstrated that it is necessary and reasonable to perform corrective surgeries as early as possible to reduce medical costs both for hospitals and for patients and to preserve motive segments. Moreover, we further analysis complications in different ages and found that surgery in earlier age did not increase complication rates (Table 7). The analysis of complications revealed that fusion surgery in patients under 3 years old would not lead to higher complication rate, further supporting the safety of early fusion surgery. However, the appropriate age for surgery must be very carefully selected. In our CS series, patients with simple hemivertebrae were treated with posterior hemivertebra resection and short-segment fusion using pedicle screws no earlier than 1.5 years old, as previous studies have indicated. Good correction rates were obtained in these patients, with few complications. Based on our clinical experience, we also found that young children treated with osteotomy and short-segment fusion grew to a height similar to that of their healthy peers after skeletal maturity. For other patients, if the congenital deformity was limited to a small region, or if the main cause of spinal deformity was limited, we adopted a strategy of early posterior osteotomy and short-segment fusion to eliminate the cause of spinal deformity and correct local scoliosis. The outcomes of these patients were satisfactory. However, we also found that osteotomy surgery was correlated with significantly higher incidences of $\mathrm{EBL}>800 \mathrm{ml}$ (Table 6). Therefore, it is better to perform comprehensive consideration preoperatively and conduct osteotomy surgery by experienced surgeons.

Theoretically speaking, early resection of congenital vertebral deformities and correction of scoliosis are beneficial to prevent the development of severe local deformities and secondary curves. Once secondary curves become structured, the extension of instrumented fused segments to comprise these curves is unavoidable. Earlier surgeries lead to milder deformities, shorter fusion segments and better outcomes. This strategy of early surgery is effective, particularly for CS patients with a single hemivertebra, in which case the hemivertebra is the only cause of deformity. As long as hemivertebrae are completely resected and local scoliosis is appropriately corrected, there was no risk of further progression and the formation of structured secondary curves [16]. This procedure also enables surgeons to preserve the motive segments and allows for normal growth in the unaffected parts of the spine.

Chang et al. [12] demonstrated the safety and effectiveness of posterior hemivertebra resection and shortsegment fusion using segmental pedicle screw fixation in CS patients younger than 10 years at the time of the surgery with a mean follow-up of 11.4 years. No crankshaft phenomenon, spinal stenosis or major complications related to the pedicle screws were found during the follow-up period. As very little growth potential of the spinal canal remains after 3 years of age [17], the authors suggested that pedicle screw instrumentation later than 2 years of age would prevent the occurrence of spinal stenosis. They also concluded that patients treated with earlier hemivertebra excision and posterior shortsegment fusion with pedicle screws before the age of 6 years had better outcomes than those aged 7 to 10 years. In another CS series, Crostelli et al. [18] performed posterior hemivertebra resection and short-segment fixation using pedicle screws in 15 patients aged 18 months to 9.5 years, concluding that this procedure led to significant advances in congenital deformity control and a low rate of neurological complications for patients as young as 18 months old. This result is in accordance with those of other independent studies [11, 19-24]. The appropriate age at surgery is generally recommended to be 1.5 to 2 years old. Except for patients with simple hemivertebrae, Ruf et al. [24] also found that posterior osteotomy with short-segment fusion using transpedicular instrumentation had good efficacy and safety to treat young patients with bar formation.

We also found that thoracic deformity was a risk factor for extended LOS, longer fused segments and higher medical costs, with an odds ratio from 1.67 to 11.30 (Figs. 1, 3 and 4). In our previous clinical practice, we found that thoracic deformities are associated with more failure of segmentation and mixed defects and that the curvatures are usually more severe than cervical and lumbar deformities. Moreover, thoracic deformities were found to have higher incidences of musculoskeletal [25] and intraspinal defects $[26,27]$. Thus, because of the restriction of the thoracic cage and the negative effect of musculoskeletal defects, such as parallel ribs, patients with thoracic vertebral malformations tend to have more complex cases and more severe deformities, requiring more challenging surgeries with higher grade osteotomies and longer fused segments. This might help to explain the association between thoracic deformity and extended LOS, longer fused segments and higher medical costs found in our study. 
Other identified risk factors include musculoskeletal defects for extended LOS (Fig. 1) and CS type (FF and MD) and sex (male) for more EBL (Fig. 2). Patients with failure of formation and mixed defects usually require surgeons to perform osteotomies to resect hemivertebrae or other congenital malformations and thus risk more perioperative blood loss. These several risk factors should be taken into consideration by surgeons in their preoperative planning and patient informing.

Generally, the strategy of early surgery is effective and safe for CS patients with local congenital vertebral malformations to minimize deformities at surgery, fusion segments, surgical trauma and medical costs. In our clinical practice, these patients, who underwent early osteotomy and short-segment fusion, were observed to have growth potential that was similar to that of their healthy peers. Thus, for CS patients with local congenital vertebral malformation and limited scoliosis, we recommended that spinal surgery be performed as early as 1.5 to 2 years of age to eliminate most forces that lead to the progression of spinal deformity. Otherwise, due to its natural history, deformities will become more severe as CS patients age and require greater surgeries and longer fusion segments, which will lead to more EBL, higher costs and longer LOS.

In summary, our study has two major strengths. First, to our knowledge, this is one of the largest single-center CS cohorts to date. Second, we are the first to comprehensively analyze the association between demographic and clinical information and outcome measures in a large CS cohort treated in a single center. However, as this is a retrospective study of data extracted from medical records, the quality and reliability of the results of this study were largely influenced by the recorders, imaging interpreters and medical record quality.

\section{Conclusions}

We found that older age at surgery was a risk factor for extended LOS, more EBL, longer fused segments and higher medical costs, with the risk increasing by $5-21 \%$ for each year increase in patient age at the time of fusion surgery. Thoracic deformity is a risk factor for extended LOS, longer fused segments and higher medical costs. Other identified risk factors include musculoskeletal defects for extended LOS, CS type (FF and MD) and sex (male) for more EBL.

\section{Abbreviations}

CS: Congenital scoliosis; FF: Failure of formation; FS: Failure of segmentation; MD: Mixed defects; LOS: Length of stay; EBL: Estimated blood loss

\section{Authors' contributions}

Conceptualization, Xiran Chai and Guanfeng Lin; methodology, Xiran Chai; software, Xiran Chai; validation, Shengru Wang and Guanfeng Lin; formal analysis, Xiran Chai and Guanfeng Lin; investigation, Xiran Chai; resources, Shengru Wang, Yang Yang and Jianxiong Shen; data curation, Xiran Chai, Zhe Su, Xiaohan Ye, You Du, Xiaolin Xu and Guanfeng Lin; writing_original draft preparation, Xiran Chai; writing - review and editing, Guanfeng Lin, Yang Yang, Zhe Su and Shengru Wang; visualization, Xiran Chai; supervision, Jianguo Zhang; project administration, Jianguo Zhang; funding acquisition, Yang Yang, Shengru Wang and Jianguo Zhang. All authors have read and agreed to the published version of the manuscript. The author(s) read and approved the final manuscript.

\section{Funding}

The study was supported by grants from National Natural Science Foundation of China (No. 81972037, 81902178), National Key Research \& Development Program of China (No. 2017YFC1104902), Beijing Natural Science Foundation (No. L192015), Fundamental Research Funds for the Central Universities (No. 3332019021), China Postdoctoral Science Foundation (No. 2020M670008ZX).

\section{Availability of data and materials}

The data set in this study is partially included in another undisclosed and uncompleted study, authors of which didn't approve to share their patients' clinical data for both public and peer review purposes.

\section{Declarations}

Ethics approval and consent to participate

Approval for the study was obtained from the ethics committee at Peking Union Medical College Hospital. Due to the retrospective nature of the study, exemption of informed consent was granted by the ethics committee at Peking Union Medical College Hospital. The authors confirmed that all methods were performed in accordance with the relevant guidelines and regulations. The consent to participate is not applicable for this study.

Consent for publication

Not applicable.

\section{Competing interests}

Not applicable.

Received: 11 April 2021 Accepted: 30 July 2021

Published online: 12 September 2021

References

1. Giampietro PF, Blank RD, Raggio $\mathrm{CL}$, et al. Congenital and idiopathic scoliosis: clinical and genetic aspects. Clin Med Res. 2003;1(2):125-36. https://doi.org/10.3121/cmr.1.2.125.

2. Pahys JM, Guille JT. What's new in congenital scoliosis? J Pediatr Orthop. 2018;38(3):e172-9. https://doi.org/10.1097/BPO.0000000000000922.

3. Dimeglio A. Growth in pediatric orthopaedics. J Pediatr Orthop. 2001;21(4): 549-55.

4. McMaster MJ, Ohtsuka K. The natural history of congenital scoliosis. A study of two hundred and fifty-one patients. J Bone Joint Surg Am. 1982;64(8): $1128-47$.

5. Chan G, Dormans JP. Update on congenital spinal deformities: preoperative evaluation. Spine(Phila Pa 1976). 2009;34(17):1766-74. https://doi.org/10.1 097/BRS.0b013e3181ab62d8.

6. Vitale MG, Matsumoto $H$, Bye MR, et al. A retrospective cohort study of pulmonary function, radiographic measures, and quality of life in children with congenital scoliosis: an evaluation of patient outcomes after early spinal fusion. Spine (Phila Pa 1976). 2008;33(11):1242-9. https://doi.org/10.1 097/BRS.0b013e3181714536.

7. Goldberg CJ, Gillic I, Connaughton O, et al. Respiratory function and cosmesis at maturity in infantile-onset scoliosis. Spine (Phila Pa 1976). 2003; 28(20):2397-406. https://doi.org/10.1097/01.BRS.0000085367.24266.CA.

8. Karol LA, Johnston C, Mladenov K, Schochet P. Walters P. Browne RH. Pulmonary function following early thoracic fusion in non-neuromuscular scoliosis. J Bone Joint Surg Am. 2008:90(6):1272-81. https://doi.org/10.2106/ JBJS.G.00184. 
9. Kesling KL, Lonstein JE, Denis F, et al. The crankshaft phenomenon after posterior spinal arthrodesis for congenital scoliosis: a review of 54 patients. Spine (Phila Pa 1976). 2003;28(3):267-71. https://doi.org/10.1097/01.BRS. 0000042252.25531.A4

10. Zhang H, Sucato DJ, Nurenberg P, McClung A. Morphometric analysis of neurocentral synchondrosis using magnetic resonance imaging in the normal skeletally immature spine. Spine (Phila Pa 1976). 2010;35(1):76-82. https://doi.org/10.1097/BRS.0b013e3181b790a0.

11. Ruf M, Harms J. Pedicle screws in 1- and 2-year-old children: technique, complications, and effect on further growth. Spine (Phila Pa 1976). 2002; 27(21):E460-6. https://doi.org/10.1097/00007632-200211010-00019.

12. Chang DG, Kim JH, Ha KY, Lee JS, Jang JS, Suk SI. Posterior hemivertebra resection and short segment fusion with pedicle screw fixation for congenital scoliosis in children younger than 10 years: greater than 7-year follow-up. Spine (Phila Pa 1976). 2015;40(8):E484-91. https://doi.org/10.1097/ BRS.0000000000000809.

13. Olgun ZD, Demirkiran G, Ayvaz M, Karadeniz E, Yazici M. The effect of pedicle screw insertion at a young age on pedicle and canal development. Spine (Phila Pa 1976). 2012;37(20):1778-84. https://doi.org/10.1097/BRS. 0b013e3182553ae0.

14. Xue X, Shen J, Zhang J, Li S, Wang Y, Qiu G. X-Ray assessment of the effect of pedicle screw on vertebra and spinal canal growth in children before the age of 7 years. Eur Spine J. 2014;23(3):520-9. https://doi.org/10.1007/s00586-013-3035-7.

15. Wu L, Zhang XN, Wang YS, Liu YZ, Hai Y. Risk factors for pulmonary complications after posterior spinal instrumentation and fusion in the treatment of congenital scoliosis: a case-control study. BMC Musculoskelet Disord. 2019;16(1):331. https://doi.org/10.1186/s12891-019-2708-8.

16. Aydogan M, Ozturk C, Tezer M, Mirzanli C, Karatoprak O, Hamzaoglu A. Posterior vertebrectomy in kyphosis, scoliosis and kyphoscoliosis due to hemivertebra. J Pediatr Orthop B. 2008;17(1):33-7. https://doi.org/10.1097/ 01.bpb.0000218031.75557.fo.

17. Zindrick MR, Knight GW, Sartori MJ, Carnevale TJ, Patwardhan AG, Lorenz MA. Pedicle morphology of the immature thoracolumbar spine. Spine (Phila Pa 1976). 2000;25(21):2726-35. https://doi.org/10.1097/00007632-20001101000003.

18. Crostelli M, Mazza O, Mariani M. Posterior approach lumbar and thoracolumbar hemivertebra resection in congenital scoliosis in children under 10 years of age: results with 3 years mean follow up. Eur Spine J. 2014:23(1):209-15. https://doi.org/10.1007/s00586-013-2933-z.

19. Ruf $M$, Harms J. Hemivertebra resection by a posterior approach: innovative operative technique and first results. Spine (Phila Pa 1976). 2002;27(10): 1116-23. https://doi.org/10.1097/00007632-200205150-00020.

20. Xue X, Zhao S. Posterior hemivertebra resection with unilateral instrumented fusion in children less than 10 years old: preliminary results at minimum 5-year follow-up. J Orthop Surg Res. 2018;20(1):240. https://doi. org/10.1186/s13018-018-0946-3.

21. Guo J, Zhang J, Wang S, et al. Surgical outcomes and complications of posterior hemivertebra resection in children younger than 5 years old. J Orthop Surg Res. 2016;25(1):48. https://doi.org/10.1186/s13018-016-0381-2.

22. Zhang J, Shengru W, Qiu G, Yu B, Yipeng W, Luk KD. The efficacy and complications of posterior hemivertebra resection. Eur Spine J. 2011;20(10): 1692-702. https://doi.org/10.1007/s00586-011-1710-0.

23. Ruf M, Harms J. Posterior hemivertebra resection with transpedicular instrumentation: early correction in children aged 1 to 6 years. Spine (Phila Pa 1976). 2003;28(18):2132-8. https://doi.org/10.1097/01.BRS.0000084627.57308.4A.

24. Ruf $M$, Jensen $R$, Letko $L$, Harms J. Hemivertebra resection and osteotomies in congenital spine deformity. Spine (Phila Pa 1976). 2009;34(17):1791-9. https://doi.org/10.1097/BRS.0b013e3181ab6290.

25. Ghandhari H, Tari HV, Ameri E, Safari MB, Fouladi DF. Vertebral, rib, and intraspinal anomalies in congenital scoliosis: a study on 202 Caucasians. Eur Spine J. 2015:24(7):1510-21. https://doi.org/10.1007/s00586-015-3833-1.

26. Beals RK, Robbins JR, Rolfe B. Anomalies associated with vertebral malformations. Spine (Phila Pa 1976). 1993;18(10):1329-32. https://doi.org/1 0.1097/00007632-199308000-00012

27. Basu PS, Elsebaie H, Noordeen MH. Congenital spinal deformity: a comprehensive assessment at presentation. Spine (Phila Pa 1976). 2002: 27(20):2255-9. https://doi.org/10.1097/00007632-200210150-00014.

\section{Publisher's Note}

Springer Nature remains neutral with regard to jurisdictional claims in published maps and institutional affiliations.

\section{Ready to submit your research? Choose BMC and benefit from}

- fast, convenient online submission

- thorough peer review by experienced researchers in your field

- rapid publication on acceptance

- support for research data, including large and complex data types

- gold Open Access which fosters wider collaboration and increased citations

- maximum visibility for your research: over $100 \mathrm{M}$ website views per year

At BMC, research is always in progress.

Learn more biomedcentral.com/submissions 